\title{
Cinética de fermentação ruminal de silagens de milheto
}

\author{
[Ruminal fermentation kinetics of pearl millet silages]
}

\author{
R. Guimarães $J r .{ }^{1}$, L.C. Gonçalves ${ }^{2}$, R.M. Mauricio ${ }^{3}$, L.G.R. Pereira ${ }^{4}$, T.R. Tomich ${ }^{5}$, \\ D.A.A. Pires ${ }^{6}$, D.G. Jayme ${ }^{7}$, L.F. Sousa ${ }^{8}$ \\ ${ }^{1}$ Embrapa Cerrados \\ Caixa Postal 08223 \\ 73310-970 - Planaltina, DF \\ ${ }^{2}$ Escola de Veterinária - UFMG - Belo Horizonte, MG \\ ${ }^{3}$ Fundação Ezequiel Dias - Belo Horizonte,MG \\ ${ }^{4}$ Embrapa Semi-árido - Petrolina, PE \\ ${ }^{5}$ Embrapa Pantanal - Corumbá, MS \\ ${ }^{6}$ UNIMONTES - Janaúba, MG \\ ${ }^{7}$ CEFET - Uberaba, MG \\ ${ }^{8}$ Aluno de pós-graduação - EV-UFMG - Belo Horizonte, MG
}

\begin{abstract}
RESUMO
Avaliaram-se a degradabilidade da matéria seca e a cinética de fermentação ruminal das silagens de três genótipos de milheto (BRS-1501, NPM-1 e CMS-3), por meio da técnica in vitro semi-automática de produção de gases. $\mathrm{O}$ delineamento experimental utilizado foi o de blocos ao acaso em arranjo de parcelas subdivididas. Para a comparação dos genótipos, foi utilizado o teste $\mathrm{SNK}(\mathrm{P}<0,05)$, e os parâmetros da cinética de fermentação foram ajustados ao modelo unicompartimental de France. A partir de 24 horas, a silagem do genótipo BRS-1501 foi a que apresentou maior produção acumulativa de gases. Os valores de degradabilidade da matéria seca apresentados às 96 horas de fermentação foram de 53,9\% para a silagem do BRS-1501, 51,7\% para a silagem do CMS-3 e 49,1\% para a silagem do NPM-1, sendo este o material com menor degradabilidade $(\mathrm{P}<0,05)$. Os potenciais máximos de produção de gases variaram de 145,18 para o genótipo CMS-3 a 155,02ml/g de MS para o BRS-1501. A silagem do genótipo BRS-1501 destacou-se entre as demais, em função do seu maior potencial de produção de gases e degradabilidades efetivas.
\end{abstract}

Palavras-chave: milheto, ruminante, silagem, técnica in vitro semi-automática de produção de gás, valor nutricional

\begin{abstract}
The dry matter digestibility and the fermentation kinetics of three pearl millet genotypes silages (BRS-1501, $N P M-1$, and CMS-3) were estimated by the semi-automated in vitro gas production technique, using a completely randomized blocks design in a split plot arrangement. The genotypes means were compared by SNK test $(P<0.05)$ and fermentation kinetics parameters estimated by regression of gas production on time using the France model. The greater cumulative gas production from 24 hours on was obtained by BRS-1501 genotype silage. The dry matter degradability (DMD) values at 96 hours of incubation were $53.9 \%$ for BRS-1501, 51.7\% for NPM-1, and 49.1\% for CMS-3 silage. The lowest DMD $(P<0.05)$ among the studied genotypes silages was observed for CMS-3 silage. The maximum potential of gas production ranged from $145.18 \mathrm{ml} / \mathrm{g}$ of dry matter for CMS-3 genotype silage to $155.02 \mathrm{ml} / \mathrm{g}$ of dry matter for BRS-1501 silage. The BRS-1501 genotype silage showed the highest potential of gas production and effective degradabilities.
\end{abstract}

Keywords: pearl millet, ruminant, silage, semi-automated in vitro gas production technique, nutritional value

Recebido em 08 de outubro de 2007

Aceito em 11 de setembro de 2008

E-mail: guimarães@cpac.embrapa.br 


\section{INTRODUÇÃO}

O milheto é uma forrageira de clima tropical, rústica, adaptada a plantios de safrinha e a regiões com regime pluviométrico irregular (Khairwal et al., 1990). Trata-se de um cereal de grande importância mundial, sendo considerado uma excelente alternativa para produção de grãos e forragem (Café et al., 2002). No mundo, o milheto é cultivado em aproximadamente 26 milhões de hectares e, no Brasil, a área plantada total é de cerca de 2,1 milhões de hectares (Bonamigo, 1999). Nessa área, a cultura do milheto destina-se à produção de palhada para plantio direto, implantação e recuperação de pastagens, produção de forragem para pastejo e para produção de grãos e silagem.

Face às suas características agronômicas e nutricionais, o milheto apresenta-se como opção forrageira para produção de silagem, podendo ser plantado estrategicamente em regiões com problemas de veranico ou seca ou em plantios de sucessão (Andrade e Andrade, 1982; Pereira et al., 1993), sendo capaz de produzir alimento suplementar em quantidade e qualidade satisfatórias durante esse período do ano (Guimarães Jr., 2003).

O número de cultivares de milheto lançados no mercado tem aumentado ultimamente, o que torna necessária melhor avaliação nutricional desses materiais na forma de silagem. Alguns trabalhos descrevem o valor nutritivo de silagens de milheto (Seiffert e Prates, 1978; Messman et al., 1992; Almeida et al., 1993; Bishnoi et al., 1993; Chaves, 1997; Amaral, 2003; Guimarães Jr., 2003), no entanto, poucos são os estudos relacionados ao comportamento desse alimento durante o processo de fermentação ruminal.

A determinação das características de fermentação ruminal de genótipos de milheto é de fundamental importância, pois essas geram informações relativas ao valor nutritivo do alimento e direcionam os programas de melhoramento genético de cultivares a serem utilizadas na dieta de ruminantes. Por meio desses estudos, é possível se avaliar a quantidade de nutrientes que estará disponível para os microrganismos do rúmen e a quantidade de nutrientes que chega ao intestino, parâmetros importantes na avaliação nutricional de alimentos para ruminantes (Nutrient..., 2001).
O objetivo deste estudo foi avaliar a degradabilidade da matéria seca e a cinética de fermentação ruminal das silagens de três genótipos de milheto, determinadas por meio da técnica in vitro semi-automática de produção de gases (Maurício et al., 1999).

\section{MATERIAL E MÉTODOS}

Os genótipos de milheto BRS-1501, NPM-1 e CMS-3 foram cultivados nas dependências da Embrapa Milho e Sorgo, em Sete Lagoas, MG. Cem dias após o plantio, os materiais foram cortados manualmente, reduzidos ao tamanho de partícula de aproximadamente $2 \mathrm{~cm} \mathrm{e,} \mathrm{em}$ seguida, ensilados em tambores metálicos com capacidade para $200 \mathrm{~kg}$, dotados de tampas. O ensaio de digestibilidade pela técnica in vitro semi-automática de produção de gases foi realizado no Laboratório de Nutrição da Escola de Veterinária da Universidade Federal de Minas Gerais. As silagens utilizadas no estudo foram amostradas uniformemente no material ensilado, após 60 dias de ensilagem, quando os tambores foram abertos. As silagens dos genótipos BRS1501, NPM-1 e CMS-3, utilizadas no ensaio, apresentaram, respectivamente, os seguintes valores de matéria seca (MS), proteína bruta (PB), fibra em detergente neutro (FDN) e fibra em detergente ácido (FDA): 21,3, 22,7, 20,1\%; $11,8,10,7,11,4 \% ; 70,5,71,2,71,0 \% ; 37,7,39,7$, $39,4 \%$.

Uma amostra representativa de cada tratamento foi submetida à pré-secagem em estufa de ventilação forçada a $65^{\circ} \mathrm{C}$ por 72 horas e, posteriormente, moído em moinho com peneira de $1 \mathrm{~mm}$. Um grama desses materiais foi incubado em frascos de vidro com capacidade de $160 \mathrm{ml}$. Para cada frasco, foram adicionados manualmente $90 \mathrm{ml}$ de meio de cultura conforme Theodorou et al. (1994). Os frascos foram vedados com rolhas de borracha $(14 \mathrm{~mm})$ e essas seladas com anilhas de alumínio. A inoculação foi feita com líquido ruminal obtido em ovinos, sendo utilizados inóculos obtidos de três animais diferentes (blocos) e um pool desses três inóculos, que deu origem ao quarto bloco. A dieta dos animais era constituída de feno de "Coast-cross" (Cynodon spp.) à vontade e $300 \mathrm{~g} /$ dia de concentrado comercial com $20 \%$ PB (base de milho, farelo de soja e minerais). Após a inoculação, os frascos foram manualmente 
agitados e colocados em estufa a $39^{\circ} \mathrm{C}$. A pressão originada pelos gases foi medida com auxílio de um transdutor de pressão ${ }^{1}$ conectado em sua extremidade a uma agulha $(25 \mathrm{~mm} \times 7 \mathrm{~mm})$. As leituras de pressão foram tomadas nos horários de $2,4,6,8,10,12,15,19,24,30,36,48,72$ e 96 horas após o início da inoculação. Foram utilizados 11 frascos (três repetições por genótipo, além de dois brancos), em cada tempo (5), para quatro diferentes inóculos, sendo 55 frascos para cada um dos inóculos utilizados, perfazendo um total de 220 frascos. A partir da inserção da agulha na tampa de silicone, a pressão produzida no interior dos frascos foi lida no leitor digital e registrada em planilhas para cálculos posteriores do volume de gases pela equação matemática sugerida por Maurício et al. (2003):

$\mathrm{V}(\mathrm{ml})=0,051 \mathrm{P}^{2}+4,43 \mathrm{P}-0,004$

em que,

$\mathrm{V}=$ volume de gases produzido $(\mathrm{ml})$; e $\mathrm{P}=$ pressão $\left(\mathrm{lb} / \mathrm{pol}^{2}\right)$.

A fração degradada da matéria seca (DMS) foi obtida pela relação entre a porcentagem do material inicialmente incubado e o resíduo após os períodos de 6, 12, 24, 48 e 96 horas de fermentação. $\mathrm{O}$ resíduo da degradação foi obtido por meio da filtragem do conteúdo de cada frasco (retirados após os períodos de incubação definidos) em cadinhos de porosidade média/grossa e posterior secagem em estufa a $100^{\circ} \mathrm{C}$ por 12 horas.

O delineamento experimental foi o de blocos inteiramente ao acaso em arranjo de parcelas subdivididas adotando-se para formação de blocos os inóculos. As parcelas foram constituídas pelos genótipos (BRS-1501, NPM-1 e CMS-3) e as subparcelas pelos tempos, o que resultou em 36 graus de liberdade no erro b. Para comparação das médias dos genótipos, no mesmo período de fermentação, utilizou-se o teste SNK $(\mathrm{P}<0,05)$. Já os dados de degradabilidade da matéria seca ao longo dos períodos de fermentação foram analisados por regressão (User's..., 2000). O seguinte modelo estatístico foi adotado:

$Y i j k=\mu+B i+E j+B E i j+T k+E T j k+e i j k$ em que,

${ }^{1}$ Bailey \& Mackey (T443A) - Birmingham, Inglaterra. $\mu=$ constante

$\mathrm{Bi}=$ efeito do bloco $\mathrm{i}, \mathrm{i}=1,2,3,4$

$\mathrm{Ej}=$ efeito do genótipo $\mathrm{j}, \mathrm{j}=1,2,3$

BEij = efeito da interação bloco vs genótipo (erro a)

$\mathrm{Tk}=$ efeito do tempo de fermentação $\mathrm{k}, \mathrm{k}=1,2,3$,

4,5

Etjk = efeito da interação genótipo $v s$ tempo de

fermentação

eijk = erro tipo b

Os dados de produção acumulativa de gases de cada genótipo nos distintos tempos de fermentação foram ajustados ao modelo de France et al. (1993) com auxílio do software Maximun Likelihood Program (Ross, 1980)

$Y=A\left\{1-\exp ^{[-b(t-L)-c x(\sqrt{ } t-\sqrt{ } L)]}\right\}, \quad$ (3); em que,

$Y=$ produção acumulativa de gases $(\mathrm{ml})$;

$A=$ Máxima de produção acumulada de gases (ml);

$L=$ tempo de colonização $(\mathrm{h})$;

$b\left(\mathrm{~h}^{-1}\right)$ e $c\left(\mathrm{~h}^{-0,5}\right)=$ taxas fracionais constantes; e $\mathrm{t}=$ tempo (h).

A taxa fracional média $\left(\mathrm{h}^{-1}\right)$ de produção de gases $(\mu)$ foi calculada como:

$\mu=b+\frac{c}{2 \sqrt{t}}$

(4); em que,

$\mu=$ taxa de produção de gases $\left(\mathrm{h}^{-1}\right)$; sendo os demais termos definidos anteriormente.

As degradabilidades efetivas (DEMS) empregando as taxas de passagem de 2,5 e $8 \% / h$ para baixo, médio e alto consumo, respectivamente, conforme recomendações do ARC (The Nutrient..., 1984) foram calculadas pela equação (5) proposta por France et al. (1993), utilizando o software MLP (Ross, 1980).

$D E M S=S_{0} e^{-k T}(1-k I) /\left(S_{0}+U_{0}\right)$ em que,

$k=$ taxa de passagem;

$S_{0}$ e $U_{0}=$ frações inicialmente fermentáveis e frações não fermentáveis, respectivamente; sendo:

$I=\int_{L}^{\infty} \exp -[(b+k)(t-T)+c(\sqrt{ } t-\sqrt{T})] d t$

A comparação das curvas de produção de gases de cada tratamento foi realizada pelo teste de paralelismo e igualdade de acordo com Ross (1980). 


\section{RESULTADOS E DISCUSSÃO}

Na Tab. 1 encontram-se as produções acumulativas de gases e as degradabilidades da matéria seca das silagens de milheto, após 6, 12, 24, 48 e 96 horas de fermentação.

Com relação às produções acumulativas de gases, no período de seis horas não foram verificadas diferenças significativas entre as silagens dos genótipos $(\mathrm{P}>0,05)$, no entanto, no período de 12 horas, a silagem do genótipo CMS-3 se mostrou inferior às demais $(\mathrm{P}<0,05)$. Do período de 24 até 96 horas, a silagem do genótipo BRS-1501 se destaca, apresentando as maiores produções acumulativas de gases $(\mathrm{P}<0,05)$ quando comparado às silagens dos genótipos NPM-1 e CMS-3, que por sua vez foram semelhantes $(\mathrm{P}>0,05)$. As produções acumulativas apresentadas no período de 96 horas foram de $157,7 \mathrm{ml} / \mathrm{g}$ de MS para a silagem do BRS$1501,147,6 \mathrm{ml} / \mathrm{g}$ de MS para a silagem do NPM-1 e $147,3 \mathrm{ml} / \mathrm{g}$ de MS para a do CMS-3. As comparações entre as silagens dos genótipos nos diferentes períodos de fermentação indicam que, a partir de 24 horas, a silagem do genótipo BRS-1501 foi a que apresentou maior fermentação. $\mathrm{O}$ mesmo pode ser observado na Fig. 1, em que é demonstrada a superioridade $(\mathrm{P}<0,05)$ da curva obtida para a silagem do genótipo BRS-1501, quando comparado às curvas dos genótipos CMS-3 e NPM-1, as quais foram semelhantes $(\mathrm{P}>0,05)$ pelo teste de paralelismo e igualdade (Ross, 1980).

Quanto às degradabilidades da matéria seca, no período inicial de fermentação (seis horas) a silagem do genótipo NPM-1 apresentou menor DMS quando comparado à do BRS-1501 $(\mathrm{P}<0,05)$, porém foi estatisticamente semelhante à silagem do CMS-3, que por sua vez foi semelhante ao BRS$1501(\mathrm{P}>0,05)$. Às 12 horas não foram observadas diferenças significativas entre os materiais $(\mathrm{P}>0,05)$. No período de 24 horas, os genótipos BRS-1501 (39,4\%) e CMS-3 (37,1\%) foram semelhantes estatisticamente entre si e superiores ao NPM-1 $(34,4 \%)(\mathrm{P}<0,05)$. Após 48 horas, o BRS-1501 foi semelhante estatisticamente quando comparado ao CMS-3 e superior ao NPM-1, no entanto, os dois últimos não apresentaram diferenças estatísticas entre si $(\mathrm{P}>0,05)$. $\mathrm{O}$ comportamento de resposta verificado no período final de fermentação (96 horas) foi igual ao encontrado no período de 24 horas, e valores de DMS apresentados foram de 53,9\% para o BRS$1501,51,7 \%$ para o CMS-3 e 49,1\% para o NPM-1, sendo este o material com menor degradabilidade $(\mathrm{P}<0,05)$.

As diferenças na ordem de superioridade dos genótipos entre a PCG e DMS podem ser explicadas pelo fato de, na técnica gravimétrica (DMS), a parte solúvel do alimento pode ser considerada instantaneamente degradada, o que não é contemplado na PCG, onde a fração solúvel permanece no frasco e sua cinética de fermentação pode interferir no volume de gases produzidos.

$\mathrm{O}$ efeito do período de fermentação sobre a degradabilidade da matéria seca das silagens de milheto foi descrito pelas seguintes equações de regressão:

DMS (\%) NPM -1 = 11,54 + 1,01T-0,006 ${ }^{2}$ $\left(R^{2}=0,97, P<0,001\right)$

$D M S(\%) B R S-1501=14,42+1,05 T-0,006 T^{2}$

$\left(R^{2}=0,96, P<0,001\right)$

$D M S(\%) C M S-3=12,30+1,06 T-0,006 T^{2}$ $\left(R^{2}=0,96, P<0,001\right)$

em que,

DMS = degradabilidade da matéria seca (\%) e $\mathrm{T}=$ período de fermentação (horas).

O modelo quadrático foi o que melhor descreveu as curvas de fermentação, evidenciando diferenças significativas $(\mathrm{P}<0,001)$ para a DMS, ao longo do tempo, em todas as silagens avaliadas.

Na Fig. 2, encontram-se as curvas de produção de gases por hora das silagens dos três genótipos de milheto. Com base neste gráfico observa-se que as maiores produções de gases por hora foram obtidas aproximadamente no período de seis horas de fermentação, fato provavelmente ligado à fermentação dos carboidratos prontamente disponíveis. Já entre os períodos de 14 e 24 horas, observa-se uma segunda elevação na produção de gases por hora que pode estar relacionada à fermentação dos carboidratos fibrosos. Sendo assim, pode-se sugerir que as silagens dos genótipos BRS-1501 e o NPM-1 são as que provavelmente possuem maior concentração de carboidratos solúveis, pois apresentaram a primeira curva do gráfico mais elevada (Castro et al., 2007). Já a degradabilidade da fração fibrosa da silagem do NPM-1 possivelmente é menor quando comparada às demais, que apresentaram maiores elevações na segunda curva do gráfico. 
Tabela 1. Produções acumulativas de gases (PCG), em ml/g de matéria seca (MS) (corrigidas para $1 \mathrm{~g}$ de MS), e degradabilidades da MS, em porcentagem (DMS), após seis, 12, 24, 48 e 96 horas de fermentação das silagens de três genótipos de milheto

\begin{tabular}{lccccc}
\hline \multirow{2}{*}{ Genótipos } & \multicolumn{5}{c}{ Períodos de fermentação } \\
\cline { 2 - 6 } & 6 & 12 & 24 & 48 & 96 \\
\cline { 2 - 6 } NPM-1 & $12,1 \mathrm{a}$ & $35,5 \mathrm{a}$ & $82,9 \mathrm{~b}$ & $123,7 \mathrm{~b}$ & $147,6 \mathrm{~b}$ \\
BRS-1501 & $12,4 \mathrm{a}$ & $35,6 \mathrm{a}$ & $88,5 \mathrm{a}$ & $132,8 \mathrm{a}$ & $157,7 \mathrm{a}$ \\
CMS-3 & $10,5 \mathrm{a}$ & $29,5 \mathrm{~b}$ & $80,0 \mathrm{~b}$ & $122,6 \mathrm{~b}$ & $147,3 \mathrm{~b}$ \\
\hline & & & DMS & & \\
NPM-1 & $16,8 \mathrm{~b}$ & $22,2 \mathrm{a}$ & $34,4 \mathrm{~b}$ & $43,9 \mathrm{~b}$ & $49,1 \mathrm{~b}$ \\
BRS-1501 & $20,0 \mathrm{a}$ & $24,6 \mathrm{a}$ & $39,4 \mathrm{a}$ & $47,6 \mathrm{a}$ & $53,9 \mathrm{a}$ \\
CMS-3 & $17,8 \mathrm{ab}$ & $23,0 \mathrm{a}$ & $37,1 \mathrm{a}$ & $45,8 \mathrm{ab}$ & $51,7 \mathrm{a}$ \\
\hline
\end{tabular}

Valores seguidos por letras distintas na coluna diferem entre si ( $\mathrm{P}<0,05)$ (PCG: $\mathrm{CV}=4,04 \%$; $\mathrm{DMS}$ : $\mathrm{CV}=4,6 \%)$.

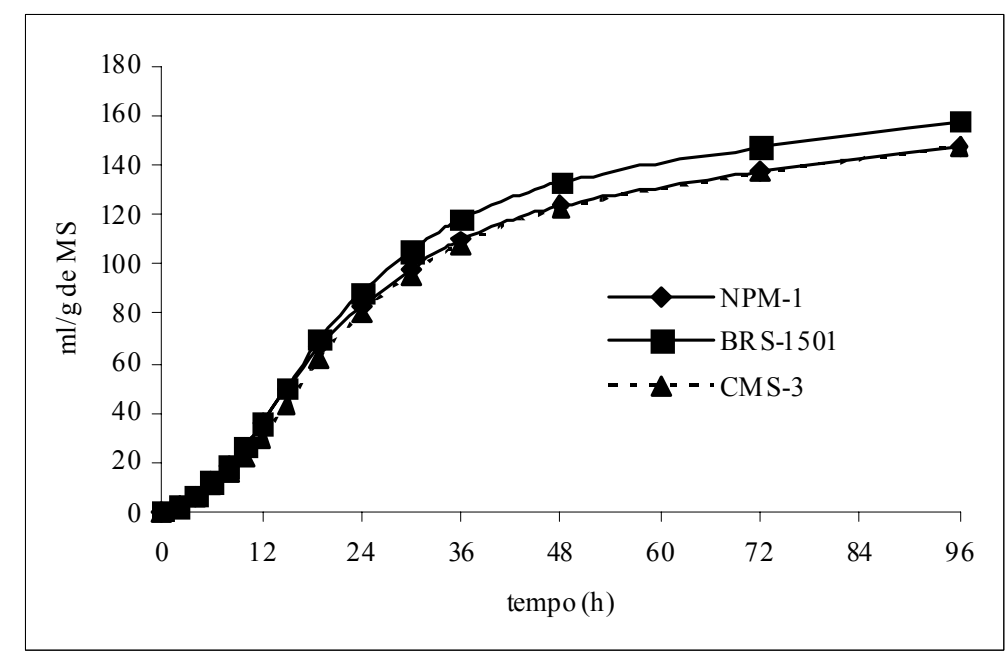

Figura 1. Produções acumulativas de gases (ml/g MS) das silagens de três genótipos de milheto.

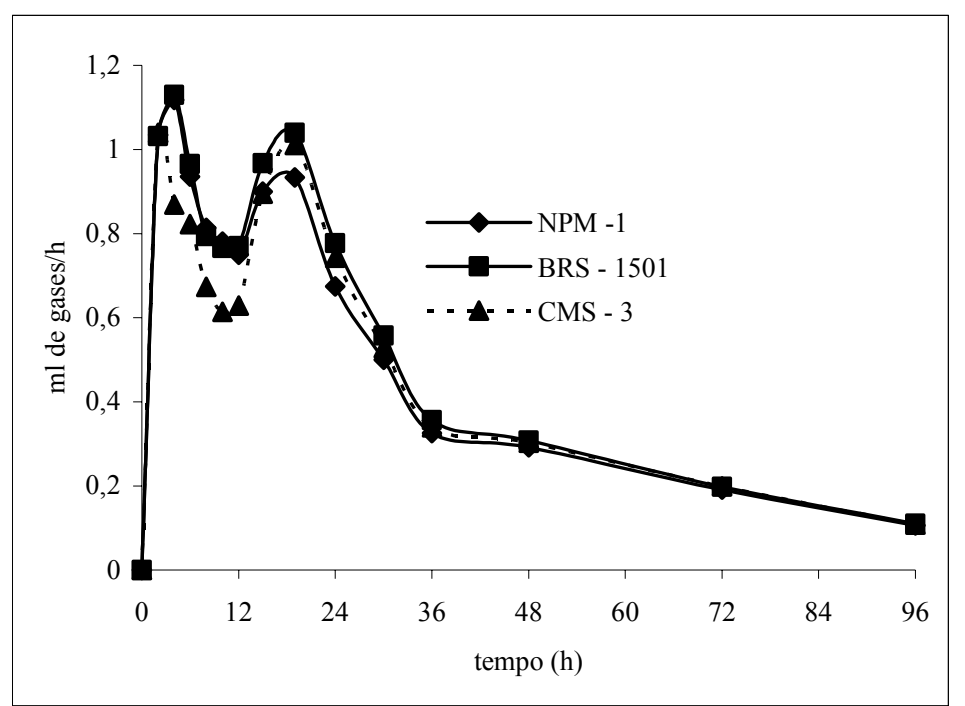

Figura 2. Produções de gases por hora (ml/g MS) das silagens de três genótipos de milheto. 
Os parâmetros da cinética de produção de gases e degradabilidade efetiva, determinados pelo modelo de France et al. (1993), referentes à matéria seca das silagens de milheto, encontramse na Tab. 2.

Os potenciais máximos de produção de gases variaram de 145,18 para o genótipo CMS-3 a $155,02 \mathrm{ml} / \mathrm{g}$ de MS para o BRS-1501, demonstrando que este material foi o que expressou a maior degradação ruminal, sem considerar o tempo de permanência da digesta dentro do rúmen. De acordo com Cone e Van Gelder (1999), comparações com outros tipos de substratos avaliados por essa técnica, com o objetivo de situar a qualidade dos híbridos testados, devem ser evitadas, visto que as diferenças no teor protéico e na relação acetato/propionato, determinada pela fermentação do alimento analisado (Getachew et al., 1998; Nogueira et al., 2006), podem influenciar o volume de gases produzido, sem necessariamente estar relacionado à degradação, ou à qualidade do alimento.

Tabela 2. Potencial máximo de produção de gases (A) em $\mathrm{ml} / \mathrm{g}$ de $\mathrm{MS}$, tempo de colonização em horas e minutos, taxa de produção de gases $(\mu) \mathrm{em} \mathrm{ml} / \mathrm{g}$ de $\mathrm{MS} / \mathrm{h}$ e degradabilidade efetiva da matéria seca $(\% \mathrm{da}$ MS) para as taxas de passagem $2,0 \%, 5,0 \%$ e $8 \%$ das silagens de três genótipos de milheto

\begin{tabular}{cccc}
\hline \multirow{2}{*}{ Parâmetros } & \multicolumn{3}{c}{ Genótipos } \\
\cline { 2 - 4 } & NPM-1 & BRS-1501 & CMS-3 \\
\hline A (ml/g de MS) & 145,80 & 155,02 & 145,18 \\
L (h:min) & $2: 02$ & $2: 30$ & $2: 44$ \\
$\mu(\mathrm{ml} / \mathrm{g} \mathrm{MS} / \mathrm{h})$ & 0,025 & 0,023 & 0,021 \\
$\mathrm{R}^{2}$ & 0,99 & 0,99 & 0,99 \\
$\mathrm{DE} 2,0 \% / \mathrm{h}(\%)$ & 32,22 & 35,03 & 33,08 \\
$\mathrm{DE} 5,0 \% / \mathrm{h}(\%)$ & 20,52 & 21,60 & 19,61 \\
$\mathrm{DE} 8,0 \% / \mathrm{h}(\%)$ & 14,92 & 14,67 & 12,72 \\
\hline
\end{tabular}

O tempo de colonização (TC) representa o tempo compreendido entre o início da incubação até a ação microbiana sobre a amostra testada. As reduções no tempo de colonização são favorecidas pela presença de substratos prontamente fermentáveis e por características físicas e químicas da parede celular da amostra. No presente trabalho, o menor tempo de colonização foi verificado para a silagem do genótipo NPM-1, sendo seguido pelo BRS-1501 (duas horas e 30 minutos) e pelo CMS-3 (duas horas e 44 minutos). O padrão de resposta verificado neste parâmetro é coerente com o que foi observado na Fig. 2, em que o BRS-1501 e o NPM-1 apresentaram o maior pico inicial de produção de gases.

De acordo com Tomich (2003), partindo do princípio de que os gases produzidos refletem a degradação da amostra testada, a taxa e o potencial máximo de produção de gases são, provavelmente, os principais parâmetros para avaliar a qualidade de forrageiras testadas pelas técnicas de produção de gases. Assim, forrageiras mais fermentáveis ou digestíveis seriam aquelas com maiores valores de potencial máximo associado a altas taxas de produção de gases, resultando numa maior fermentação do material em menor tempo de incubação. As taxas de produção de gases obtidas neste experimento foram próximas, sendo de $0,025 \mathrm{ml} / \mathrm{g}$ de $\mathrm{MS} / \mathrm{h}$ para o genótipo NPM-1, 0,023ml/g de $\mathrm{MS} / \mathrm{h}$ para o BRS-1501 e $0,021 \mathrm{ml} / \mathrm{g}$ de $\mathrm{MS} / \mathrm{h}$ para o CMS-3.

As degradabilidades efetivas calculadas com base nos parâmetros obtidos pelo modelo de France et al. (1993) associadas aos resultados de degradabilidade da MS após 96 horas mostram que a silagem do genótipo BRS-1501 foi superior às demais, entretanto, com o aumento da taxa de passagem, as diferenças foram minimizadas, principalmente quando este genótipo foi comparado ao NPM-1, fato explicado pelo seu menor tempo de colonização. Para taxas de passagem simulando animais em nível de mantença $(2 \% / \mathrm{h})$, nível médio de produção $(5 \% / \mathrm{h}$ - equivalente à observada para ovinos em crescimento) e alto nível de produção $(8 \% / \mathrm{h})$, alimentados com dietas mistas, os valores de DE variaram de $12,72 \%$ para a silagem do NPM-1 a uma taxa de $8,0 \% / \mathrm{h}$ a $35,03 \%$ para a do BRS-1501 a uma taxa de $2 \% / \mathrm{h}$. 


\section{CONCLUSÕES}

A silagem do genótipo BRS-1501 se destacou entre as demais, em função da sua maior produção acumulativa de gases, do seu maior potencial de produção de gases e maiores degradabilidades efetivas para as taxas de 2 e $5 \% / \mathrm{h}$.

\section{REFERÊNCIAS BIBLIOGRÁFICAS}

ALMEIDA, E.X.; TCACENCO, F.A.; STUCKER, H. et al. Avaliação de cultivares de sorgo, milho, milheto e teosinto para o vale do Itajaí. Agrop. Catarinense, v.6, p.25-29, 1993.

AMARAL, P.N.C. Silagem e rolão de milheto em diferentes idades de corte. 2003. 78f. Dissertação (Mestrado) Universidade Federal de Lavras, Lavras.

ANDRADE, J.B.; ANDRADE, P. Produção de silagem de milheto (Pannisetum americanum (L.) K. Schum.). Bol. Ind. Anim., v.39, p.67-73, 1982.

BISHNOI, U.R.; OKA, G.M.; FEARON, A.L. Quantity and quality of forage of pearl millet in comparison to Sudax, grain and forage sorghuns harvested at different growth stages. Trop. Agric., v.70, p.98-102, 1993.

BONAMIGO, L.A. A cultura do milheto no Brasil, implantação e desenvolvimento no cerrado. In: WORKSHOP INTERNACIONAL DE MILHETO, 1999, Brasília. Anais... Brasília: Embrapa, 1999, p.31-65.

CAFÉ, M.B.; STRINGHINI, J.H.; FRANÇA, A.F.S. Utilização do milheto na alimentação animal. In: SIMPÓSIO SOBRE INGREDIENTES NA ALIMENTAÇÃO ANIMAL, 2., 2002. Uberlândia. Anais... Uberlândia: Colégio Brasileiro de Nutrição Animal, 2002. p.5-38.

CASTRO, G.H.F.; GRAÇA, D.S.; GONÇALVES, L.C. et al. Cinética de degradação e fermentação ruminal da Brachiaria brizantha $\mathrm{cv}$. Marandu colhida em diferentes idades ao corte. Arq. Bras. Med. Vet. Zootec., v.59, p.1538-1544, 2007.

CHAVES, C. Produção e valor nutritivo das silagens de capim sudão [Sorghum sudanense (Piper) Stapf, milheto (Pennisetum americanum (L.) Leeke], teosinto (Euchlaena mexicana Schrad) e milho (Zea mays L.). 1997. 56f. Dissertação (Mestrado) - Universidade Federal de Lavras, Lavras.

CONE, J.W.; VAN GELDER, A.H. Influence of protein fermentation on gas production profiles. Anim. Feed Sci. Technol., v.76, p.251-264, 1999.

FRANCE, J.; DHANOA, M.S.; THEODOROU, M.K. et al. A model to interpret gas accumulation profiles associated with in vitro degradation of ruminant feeds. J. Theor. Biol., v.163, p.99-111, 1993.

GETACHEW, G.; BLÜMMEL, M.; MAKKAR, H.P.S. et al. In vitro gas measuring techniques for assessment of nutrition quality of feeds: a review. Anim. Feed Sci. Technol., v.72, p.261-281, 1998.
GUIMARÃES JR., R. Potencial forrageiro, perfil de fermentação e qualidade das silagens de três genótipos de milheto [Pannisetum glaucum (L).Rr.Br.]. 2003. 44f. Dissertação (Mestrado) - Escola de Veterinária, Universidade Federal de Minas Gerais, Belo Horizonte.

KHAIRWAL, I.S.; RAM, C.; CHHABRA, A.K. Pearl millet: seed production and technology. New Delhi: Manohar. 1990. 208p.

MAURICIO, R.M.; MOULD, F.L.; DHANOA, M.S. et al. A semi-automated in vitro gas production technique for ruminants fedstuff evaluation. Anim. Feed Sci. Technol., v.79, p.321-330, 1999.

MAURÍCIO, R.M.; PEREIRA, L.G.R.; GONCALVES, L.C. et al. Relação entre pressão e volume para implantação da técnica in vitro semi-automática de produção de gases na avaliação de forrageiras tropicais. Arq. Bras. Med. Vet. Zootec., v.55, p.216-219, 2003.

MESSMAN, M.; WEISS, W.P.; HENDERLONG, P.R. et al. Evaluation of pearl millet and field peas plus triticale silages for midlactation Dairy Cows. J. Dairy Sci., v.75, p.2759$2775,1992$.

NOGUEIRA, U.T.; MAURÍCIO, R.M.; GONÇALVES, L.C. Comparação de substratos com diferentes quantidades de carboidratos solúveis utilizando a técnica in vitro semiautomática de produção de gases. Arq. Bras. Med. Vet. Zootec., v.58, p.633-641, 2006.

NUTRIENT requirements of dairy cattle. 7.ed. Washington: National Academy, 2001. 362p.

PEREIRA, O.G.; OBEID, J.A.; GOMIDE, J.A. et al. Produtividade e valor nutritivo de aveia (Avena sativa), milheto (Pannisetum americanum) e de um híbrido de Sorghum bicolor XS sudanense. Rev. Soc. Bras. Zootec., v.22, p.22-30, 1993.

ROSS, G.J.S. Maximun Likelihood Program (A Manual). Hampendon: Tothmsted Experimental Station, 1980.

SEIFFERT, N.F.; PRATES, E.R. Forrageiras para a ensilagem. II - Valor nutritivo e qualidade de silagem de cultivares de milho (Zea mays, L.), sorgos (Sorghum sp.) e milhetos (Pannisetum americanum, Schum). Rev. Soc. Bras. Zootec., v.7, 1978.

THE NUTRIENT requirements of ruminant livestock. Suppl.1. Slough: Commonwealth Agricultural Bureaux. 1984. 45p.

THEODOROU, M.K.; WILLIAMS, B.A.; DHANOA, M.S. et al. A new gas production method using a pressure transducer to determine the fermentation kinetics of ruminal feeds. Anim. Feed Sci. Technol., v.48, p.185-197, 1994.

TOMICH, T.R. Potencial forrageiro de hibridos de sorgo com capim Sudão avaliados em regime de corte. 2003. $88 \mathrm{f}$. Tese (Doutorado) - Escola de Veterinária, Universidade Federal de Minas Gerais, Belo Horizonte.

USER'S guide statistics (SAS software). version 8.2. Cary: SAS Institute, 2000. 291p. 